\title{
Research on Resources Allocation Mechanism of Manufacturing Enterprises Base on Multi- level Programming
}

\author{
Bi Keke \\ College of Management and Economics, \\ Tianjin University, \\ Tianjin, China; \\ Ren'ai College, \\ Tianjin University, \\ Tianjin, China; \\ kekebi_kiki@126.com \\ Peng Wei \\ Key Laboratory of Mechanism Theory and Equipment \\ Design of Ministry of Education, \\ Tianjin, China; \\ pengwei_tju@163.com
}

\author{
Zhao Nan \\ College of Machinery Engineering, \\ Tianjin University of Technology and Education, \\ Tianjin, China, \\ nanzhao1982@163.com
}

\author{
Sun Jiang \\ College of Management and Economics, \\ Tianjin University, \\ Tianjin, China; \\ sunjiang_tju@163.com
}

\begin{abstract}
To improve the efficiency of resources allocation in manufacturing enterprises, a bi-level programming model for studying coordinate development of efficiency and effectiveness in functional departments is proposed based on analysis of complexity and hierarchy of manufacturing enterprises. Then an improved adaptive Harmony Search for solving the bi-level programming model is discussed. A typical state-owned manufacturing enterprise is analyzed. Results show that, the harmonious coexistence of functional departments is the necessary condition of maximization of both profits and effectiveness. The enterprises could increase investment in $R \& D$ to increase the production value when it is difficult to expand the production scale. To avoid violent fluctuations of production value, Decision makers should maintain the stability of resources input quantity.
\end{abstract}

Keywords- Manufacturing enterprises; resource allocation; bi-level programming model; adaptive harmony search; model construction.

\section{INTRODUCTION}

Manufacturing enterprise ecosystem reflects a hierarchical structure: functional layer reflects the ecological relationship between market, design, manufacturing, sales department and other departments, the goal is to maximum the benefits of all sectors; control layer reflects the regulation and constraints to functional layer, to pursue efficient resource allocation. Thus, the manufacturing enterprise ecosystem with multiple goals and interactivity, complexity in the allocation of resources to the various functional departments, can be attributed to a master-slave dynamic game problem. Current research on manufacturing enterprise resource allocation hierarchy is not much, mainly in terms of allocative efficiency. According to the existing research on configuration, administration and configuration mode often make inefficient because of excessive protection ${ }^{[1]}$; In the management methods, state-owned enterprises are easier to access to large-scale credit resources and occur the phenomenon that produce excessive investment ${ }^{[2]}$; Unreasonable employment demand, along with unbalanced staff structural caused the low efficiency of human resources $^{[3]}$ 。 In the aspect of evaluation methods of allocation efficiency, DEA, malmquist index approach, the input-output model and marginal analysis are mainly applied. Huihua Nie etc. ${ }^{[4]}$ analzed the data of national Enterprises and scale manufacturing enterprise from 1999 to 2007 by using OP method. Weidong Meng etc. ${ }^{[5]}$ Using the two step method of DEA-Tobit, found that the efficiency of resource allocation is positively correlated with the regional open degree, high technology industry development, investment in talent in scientific research institution and enterprise support for science and technology innovation.

Therefore, to improve the efficiency of resource allocation of manufacturing enterprises is still the current important topic of the state-owned enterprise reform. This paper established a bi-level programming model of ecological system of resource allocation of manufacturing enterprises and using the improved adaptive harmony search algorithm to discuss the solution of the model, and based on practical examples to improve the manufacturing efficiency of allocation of corporate resources, in order to realize the profit maximization, the suggestions to improve the allocation of resources were put forward. 


\section{MODEL BUILDING}

As ecosystems, corporate internal board of directors and managers carry on the internal system control for the dynamic behavior of the various subsystems while there is also competition for resources between departments. Under limited resources of the ecological system, need to control layer effective regulation and constraints of each subsystem, in order to maximize the overall resource utilization of enterprise ecological system as the goal while also keep the interest of subsystem, to achieve balanced development.

Describing this complex process relies on the bi-level programming model. In the decision-making process, the upper programming not only related to the upper programming decision variables, but also depends on the solution of optimal planning. At the same time, the optimal solution of lower planning also affected the upper decision variables $^{[6]}$ 。 The upper and lower programming model are as follows.

\section{A. Upper programming model}

This paper is based on the most common $\mathrm{BCC}$ model ${ }^{[7]}$ to establish the upper programming model, evaluated on the known resource allocation scheme respectively, the specific model is as follows:

$$
\begin{aligned}
& \min \left[\theta-\varepsilon\left(e^{T} s^{-}+e^{T} s^{+}\right)\right] \\
& \text {s.t. }\left\{\begin{array}{l}
\sum_{j=1}^{n} x_{i j} \lambda_{j}+s^{-}=\theta x_{i j_{0}},(i=1,2, \ldots, m) \\
\sum_{j=1}^{n} y_{r j} \lambda_{j}-s^{+}=y_{r j_{0}},(r=1,2, \ldots, s) \\
\lambda_{j} \geq 0,(j=1,2, \ldots, n), \theta \in E_{1}^{+}, s^{+} \geq 0, s^{-} \geq 0
\end{array}\right.
\end{aligned}
$$

In the formula, ${ }^{\theta}$ is efficiency index; ${ }^{\varepsilon}$ is the introduced slack variables; $\hat{e}=(1,1, \cdots, 1)^{T} \in E_{m}^{+}, \quad e=(1,1, \cdots, 1)^{T} \in E_{s}^{+} ; y_{r j}$ 、

$x_{i j}$ indicate the ${ }^{\tilde{I}}$ kind configuration of known input and output ; $\lambda_{j}$ is the dual variable ; $\mathrm{s}^{+} 、 \mathrm{~s}^{-}$are slack variables and the remaining variables respectively; $y_{\mathrm{rj}_{0}} 、 x_{\mathrm{i} j_{0}}$ represents a configuration scheme being evaluated. If the $f$ kind optimal solutions for the configuration is $\theta_{0}, \lambda_{0 j}, j=1,2, \ldots, n, \mathrm{~s}^{+}, \mathrm{s}^{-}$ satisify $\theta_{0}=1, s^{+}=0, s^{-}=0$, then the program is effective.

\section{B. The lower programming model}

If the production function is the form of C-D, then

$$
y_{j}=\prod_{i=1}^{m} A x_{i j}^{a_{i j}}
$$

Whereby, $y_{j}$ indicate the $\tilde{f}$ kind configuration

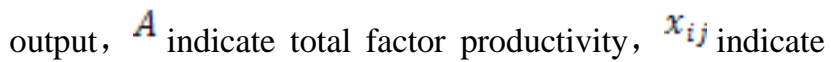
the ${ }^{i}$ kind configuration scheme of the ${ }^{i}$ kind resources of the inputs, $\alpha_{\tilde{\mathrm{I}}}$ is the output elasticity of resource According to equation (2) and other parameters, the lower programming model is as follows:

$$
\begin{gathered}
\max _{x} y_{j}=\prod_{i=1}^{m} A x_{i j}^{\alpha_{i}} \\
\text { s.t. }\left\{\begin{array}{l}
A>0 \\
x_{i j}>0 \\
\sum_{i=1}^{m} x_{i j}=P \\
a_{i}<1
\end{array}\right.
\end{gathered}
$$

In the formula, there is only one output index, ${ }^{P}$ is the total amount of resource. Elasticity ratio $\alpha_{\hat{1}}$ of resource is generally less than 1. Formula (1) and (3) constitutes a bilevel programming model for manufacturing resource allocation; upper model evaluate the efficiency of resource allocation scheme on behalf of the general distribution principles of resources of control layer; the lower model optimizes the resources allocation construction, reflecting the pursuit of economic interests of the functional layer.

\section{SOLVING ALGORITHM}

R. Jeroslow ${ }^{[8]}$ pointed out the bi-level linear programming is NP-Hard problem. There are many kinds of algorithms for solving bi-level programming, in order to further improve the optimal performance. Harmony search algorithm was put forward by South Korean scholar Geem $\mathrm{ZW}{ }^{[9]}$, which is a heuristic global search algorithm, some people including Mahdavi presented a kind of adaptive control strategy, implementing the algorithm parameters ${ }^{[10]}$. After improvement, this paper puts forward the following strategies.

1) Initialization harmony memory phase: using chaotic search strategy to generate the initial solution and chaotic variables has better ergodicity by using random variables, so that the initial solution is more evenly spread in the feasible region.

2) New Solution Generation stages: this paper learn differential evolution algorithm thought, make the strongest DE / rand / 1 / exp operator in ten differential evolution optimization mode as a means to generate a new solution. Differential evolution was a heuristic algorithm for global optimization of continuous space put forward by Stom and Price ${ }^{[11]}$.

\section{EMPIRICAL ANALYSIS}

\section{A. Essential data}

In this paper, studying a power generation equipment company in Tianjin, the company has more than twenty years of production history of hydropower facilities, with operations in multiple regions at home and abroad, which is typical of the equipment manufacturers. This paper selects the four departments that are closely associated with the product: market, $R \& D$, production and sales department, researching full business to get their sample data from 2004-2012 are shown in Table 1: 
TABLE I. THE HISTORICAL DATA OF AN EQUIPMENT MANUFACTURING ENTERPRISES (FUNDS UNIT: MILLION)

\begin{tabular}{cccccc}
\hline & \multicolumn{4}{c}{ Capital } & Output \\
\cline { 2 - 5 } & Market & R\&D & Production & $\begin{array}{c}\text { Sales } \\
\text { dep. }\end{array}$ \\
\hline 2004 & 90.70 & 38.96 & 13347.71 & 16.75 & 18958 \\
2005 & 167.39 & 116.41 & 29606.97 & 24.75 & 27028 \\
2006 & 160.27 & 14.67 & 40022.70 & 25.15 & 40100 \\
2007 & 816.86 & 1362.94 & 41904.29 & 104.88 & 45388 \\
2008 & 376.46 & 1671.42 & 30525.64 & 296.25 & 48100 \\
2009 & 904.13 & 763.10 & 23715.01 & 241.01 & 50515 \\
2010 & 2443.11 & 2029.94 & 36148.72 & 77.23 & 52851 \\
2011 & 1820.08 & 1552.53 & 35858.93 & 102.13 & 50171 \\
2012 & 1268.69 & 2122.16 & 49628.12 & 96.89 & 48840 \\
\hline
\end{tabular}

Except for the year and the value, each row in the table constitutes the input in formula (2), the output value is output, fitting SPSS software and getting value $y$ on the input function $x$ :

${ }^{1.591} x_{8}^{-0.111} y=113550.1649 x_{1}^{0.349} x_{2}^{-0.192} x_{3}^{0.3} x_{4}^{0.359} x_{5}^{-0.208} x_{6}^{0.933} x_{7}{ }^{-}$

In the formula, $x_{1}, x_{2}, x_{3}, x_{4}$ represent the capital investment. According to the data in Table 1, which can be expressed as the following table:

TABLE II. TABLE 2 THE TOTAL AMOUNT OF RESOURCES (CAPITAL UNIT: RMB 100 MILLION YUAN)

\begin{tabular}{lccccccccc}
\hline & 2004 & 2005 & 2006 & 2007 & 2008 & 2009 & 2010 & 2011 & 2012 \\
\hline Capital & 1.35 & 2.99 & 4.02 & 4.42 & 3.29 & 2.56 & 4.07 & 3.93 & 5.31 \\
\hline
\end{tabular}

\section{B. The generation of resource allocation scheme and calculated results}

When using adaptive harmony search algorithm to solve bi-level programming of formula (1) and formula (3), we must first generate a set of resource allocation scheme, and where there is equality constraints, increasing the difficulty of the problem. By solving linear programming to meet the resource allocation scheme equality constraints, the transformation of the linear programming model is as follows:

$$
\begin{aligned}
& \min \delta \\
& \text { s.t. }\left\{\begin{array}{l}
\sum_{i=1}^{m} x_{i j}+\delta=P \\
l b<x_{i j}<u b \\
\delta \geq 0
\end{array}\right.
\end{aligned}
$$

In the formula, ${ }^{\delta}$ is the slack variable; ${ }^{d b} 、 u b$ are the input variables of the lower and upper, respectively. The solution of this model has infinite pieces and randomly generated one part ${ }^{x_{i j}}$, can draw many solutions for solving linear programming method, as long as meet the condition that ${ }^{\delta}$ less than the given precision, which can get a set of feasible solution, and can generate a sufficient number of feasible scheme by iteratively solving throughout the solution space. Calculating by using MATLAB programming, we can obtain resource allocation optimization scheme of each year.

\section{Result analysis}

In order to verify the reliability of this method, the original data will be calculated from investigation and bi level planning results into the comparative analysis together. According to the characteristics of traditional equipment manufacturing enterprise, the core business is research and production, so mainly use the resource allocation mechanism of these two departments for instance.

(1) Fund allocation results

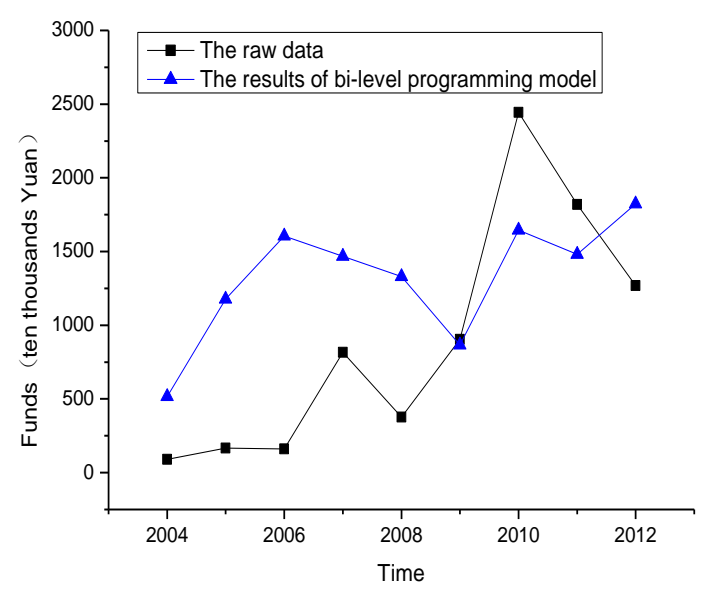

a) Marketing

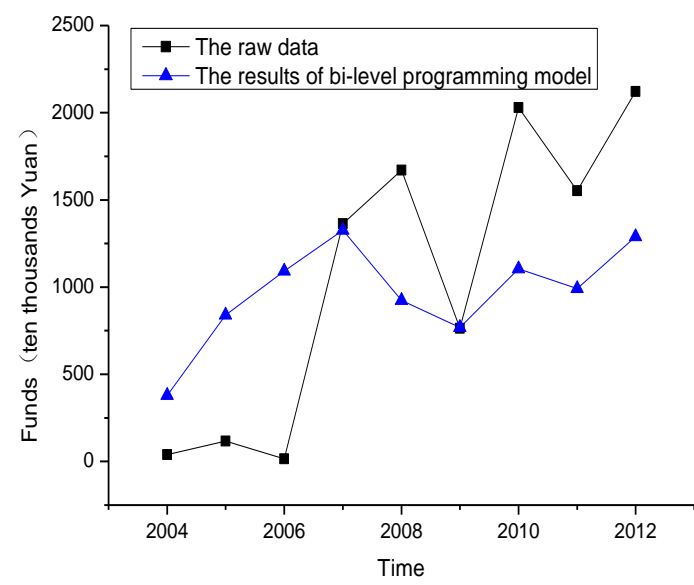

b) $\mathrm{R} \& \mathrm{D}$ 


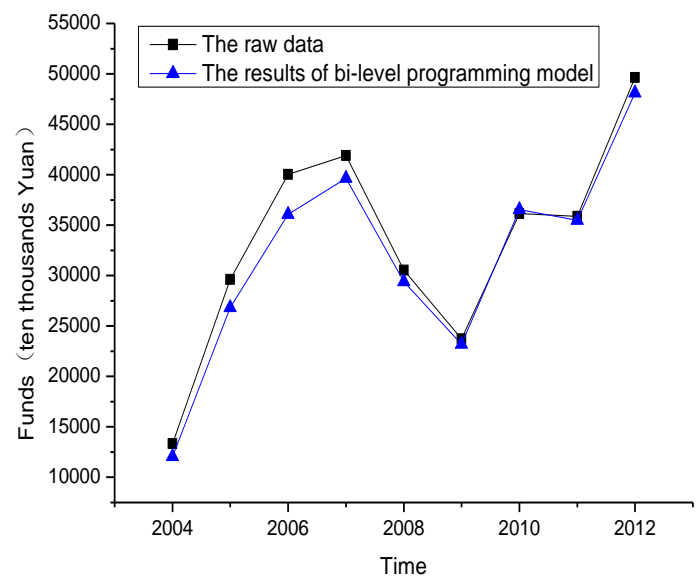

c) Production

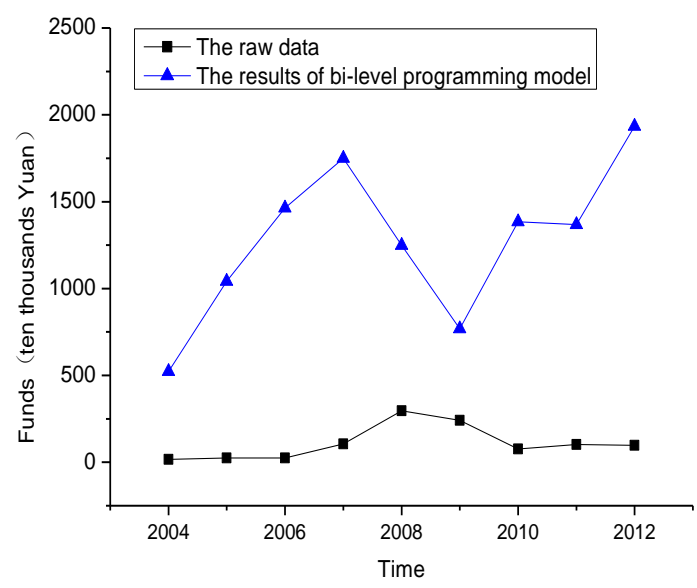

d) after-sales service Ministries

Figure 3. The simulation results of capital allocation of various departments under two circumstances.

It can be seen from Fig .3, for two groups of curves, except in the production department were close, other departments are very different. The original data does not have the rule, basically, while the bi-level programming results have similar changes in four departments, which indicate that the harmonious co-existence of departments is the direction of optimal allocation of resources. Two sets of curves in production department is relatively close, because of the amount of investment in the production department resource occupies a great proportion in the total amout and change range is small, not reflecting small differences. Compared the Calculation result of the four departments, it can be found in 2008-2009, resource input shave decreased due to the 2008 outbreak of the financial crisis, leading to the total input of resources to reduce the amount . In contrast, only the R \& D Department declined slowly, probably because the impact of the $R \& D$ Department of enterprise annual output value is larger. In order to achieve the maximization of profits, we can not make a dramatic fluctuation. Compared the results of $\mathrm{R} \&$ $\mathrm{D}$ department and the production department, we can illustrate the importance of enterprise technology, improving the technology content of products is higher than economic benefit of expansion of production scale.

(2)Annual output value of enterprises

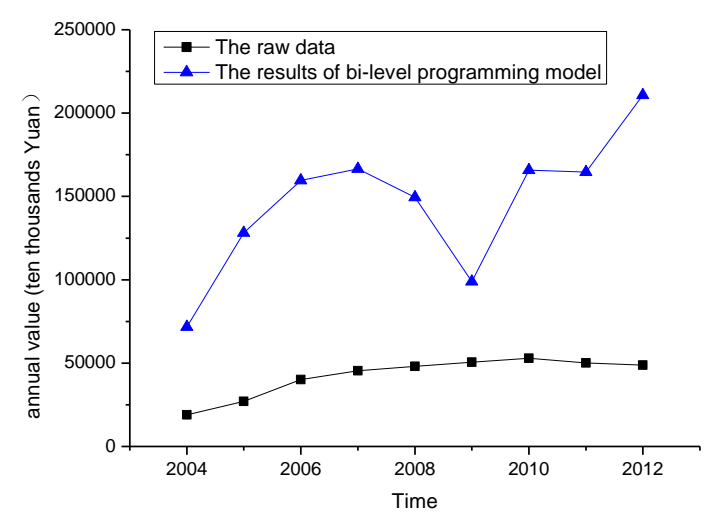

Figure 4. The simulation results of enterprises' annual output in two cases

It is shown that the calculation of the bi-level planning result is far higher than the original data, reflecting the existing enterprise value still has larger growth space. In 2009 , the calculated output was reduced to a low point, but it was still higher than the original value. It was caused by the outbreak of the financial crisis in 2008, which made the enterprise resources that can be invested substantially reduced. As we can see, when the total investment amount of resources is restored to the level before 2008, the output value rapidly rose again. It indicates that in optimal allocation of resources, we should maintain the stability of investment to avoid sharp fluctuations.

\section{Recommendations for improvement}

According to the research conclusion of this article, in the aspects of resource allocation mechanism, manufacturing enterprises are responsible for researching, coordinating, real-time monitoring and regulating and satisfying the efficient allocation of security resources by establishing professional institutions. In the specific control measures, it should be improved from the following directions:

(1)We should pay attention to optimize the allocation of resources to realize the balanced development. According to the theory and the enterprise ecosystem conclusion, as long as the enterprises realize the harmony between the various departments and share resources, we can maximize output. The balanced development of giving priority to efficiency and consideration to fair mode helps to avoid vicious competition between departments and cohesive force.

(2)Focus on $\mathrm{R} \& \mathrm{D}$ investment. In the information age, the technology content of products greatly influences the enterprise's market share and competition ability. Manufacturing enterprises should be gradually abandoned the traditional mode of growth by mainly expanding the scale of production, changing into the road of relying on scientific and technological level and the innovation ability development, paying attention to the research and development of new products and enhancing product added value.

(3)Upgrade the manufacturing level of service. At present, the manufacturing industry is gradually become service-oriented. According to the smile curve, the service 
is in the value chain and the role of service linking in the value chain of manufacturing industry will be more and more important. Manufacturing enterprises should speed up the reform in this respect, and "the production center" should be transformed into "take the service as the center". Introducing consumer into products manufacturing and application service process, we should actively percept customer demand and expanse of specific service to provide productive service and manufacturing service for the upstream and downstream customers and create value in coordination

\section{CONCLUSION}

In this paper the problem oriented enterprise ecosystem limited resource allocation decision making, based on the DEA model and production function, establishing bi-level programming model of the coordinated development on "efficiency - benefit", putting forward the multilevel programming model for solving algorithm that based on adaptive harmony search, and use an example to verify the effectiveness of the model and algorithm, the empirical results show that: Harmony between departments and sharing resources are necessary to maximize profit for the enterprise; the level of science and technology play an important role in the enterprise development, the output value can be improved by increasing $\mathrm{R} \& \mathrm{D}$ investment in the difficulty of expanding production scale; the enterprise should keep steady growth of resource inputs to avoid drastic fluctuations of output value when optimizing the allocation of resources. Finally, the specific suggestions of enterprise reform was put forward based on the conclusions of this paper: in view of the problem that current efficiency of resource allocation mechanism is not high, we should establish professional management organization of resource allocation to implement dynamic management; in the management level, we should pay attention to optimize the allocation of resources and pay attention to $\mathrm{R} \& \mathrm{D}$ investment, strengthening innovation ability and upgrading the manufacturing level of service to transform the mode of development.

\section{REFERENCES}

[1] Li Ya-xiong, Liu Hong. Discuss of the interaction between a stateowned enterprise and thegovernment_—a large national enterprise for instance[J]. Journal of Fujian Provincial Committee Party School of CPC. 2008(6): 58-61.

[2] Huang Xin-jian, Yan Hong. The effectiveness of China listed companies stock properties to credit resources allocation and efficiency_based on investment perspective[J]. Yunnan Finance \& Economics University Journal of Economics \& Management, 2012(2): 112-116.

[3] He Lei. Brief talk of the improvement of national enterprise human resource efficiency management $[\mathrm{J}]$. People's Tribune, 2012(23): 76-77.

[4] Nie Hui-hua, Jia Rui-xue. China manufacturing enterprise productivity and resource mis-placing $[\mathrm{J}]$. The Journal of World Economy, 2011(7): 27-42.

[5] Meng Wei-dong, Wang Qing. Rigional innovation system technology resource allocation efficiency influencing factors empirical analysis[J]. Statistics \& Decision, 2013(4): 96-99.

[6] Li Yan, Du Gang, Liu Bo. A robust solution of linear bi-level programming[J]. Statistics \& Decision, 2013 (1): 78-80.

[7] Duan Yong-rui. Data envelopment analysis: Theory and Application[M]. Shanghai: Shanghai Popular Science Press, 2006 5-6.

[8] Jeroslow $\mathrm{R}$, The polynomial hierarchy and a simple model for competitive analysis[J]. Mathematical Programming,1985, 32: 146-164.

[9] Geem Z W, Kim J H, Loganathan GV. A new heuristic optimization algorithm: harmony search[J]. Simulation, 2001, 76(2): 60-68.

[10] Mahdavi M, Fesanghary M, Damangir E. An improved harmony search algorithm for solving optimization problems[J]. Applied Mathematics and Computation, 2007, 188(2) : 1567-1579.

[11] Storn R, Price K. Differential evolution-A simple and efficient adaptive scheme for global optimization over continuous spaces[R]. Berkeley: University of California, 2006.

[12] Banker R D, Charnes A, Cooper W W. Some models for estimating technical and scale inefficiencies in data envelopment analysis[J]. Management science, 1984, 30(9): 1078-1092. 